Artículo

\title{
Interacción genotipo ambiente en fracciones de forraje de trigos en tres muestreos
}

\author{
Luz Oralia Ramírez Pérez \\ Víctor Manuel Zamora Villa ${ }^{\S}$ \\ Modesto Colín Rico \\ Humberto de León Castillo
}

Universidad Autónoma Agraria Antonio Narro. Calzada Antonio Narro 1923, Col. Buenavista, Saltillo, Coahuila, México. CP. 25315. (luzramirezperez00@gmail.com; zamora2602@yahoo.com.mx; modesto.colin@uaaan.mx; hleonc62@hotmail.com).

$\S^{\S}$ Autor para correspondencia: zamora2602@yahoo.com.mx.

\section{Resumen}

Los cereales invernales poseen características útiles para la producción de forraje y presentan generalmente adecuada calidad nutritiva. En la generación de nuevas variedades es necesario cuantificar la interacción genotipo ambiente (IGA) para realizar una selección más eficiente. Los objetivos fueron analizar la interacción genotipo ambiente (IGA) en fracciones de forraje de 22 líneas de trigos harineros imberbes y tres testigos comerciales de otra especie, a través de tres muestreos. Se utilizó un diseño de bloques completos al azar con tres repeticiones en cuatro ambientes, realizando muestreos a los 75, 90 y 105 días después de la siembra. Se determinó la producción de forraje seco total y de sus fracciones, analizándolos mediante el modelo AMMI. Los resultados indicaron que trece líneas de trigo junto con la cebada presentaron características deseables para producción de forraje seco total a través de los muestreos realizados de acuerdo con la superioridad sobre la media general. El testigo avena se consideró la menos productiva. La porción de tallos fue la de mayor aportación al rendimiento de forraje seco, seguida de las hojas y espigas. Hubo presencia de la IGA en las fracciones de forraje, así como en el total.

Palabras clave: estabilidad, forraje seco, fracciones de forraje, modelo AMMI, trigos sin aristas.

Recibido: enero de 2021

Aceptado: marzo de 2021 


\section{Introducción}

Los cereales invernales son una alternativa sostenible para la producción ganadera, por el eficiente uso del agua a pesar de la presencia de heladas por el cambio climático, donde el trigo posee una tolerancia al frío de hasta $-23{ }^{\circ} \mathrm{C}$ (Braun y Sãulescu, 2002). Presentan características que los hacen útiles para forraje, al producir altos rendimientos y ser ricos en proteínas, vitaminas e hidratos de carbono (Cherney y Marten, 1982; Cash et al., 2004). A nivel mundial el trigo es el más utilizado en la alimentación humana; siendo materia prima para elaborar diversidad de alimentos procesados (FAO, 2005) y empleado como alimento verde en la dieta animal en forma de forraje.

En los últimos años el uso de cereales se ha ampliado, usándolos en pastoreo, verdeo, henificado, picado y ensilado (Hughes et al., 1974; Colín et al., 2007) clasificándolos como un recurso forrajero de buena calidad (Hart et al., 1971; Juskiw et al., 2000), incluso cuando se consideran sus fracciones por separado (Zamora et al., 2016), existiendo trigos con producción similar al de la avena. Siendo la Comarca Lagunera la principal cuenca lechera de México, es una de las áreas que en épocas críticas como el invierno necesita opciones forrajeras que aseguren calidad nutritiva y permita continuar con la producción, por la existencia de diversas opciones de uso y diversos tiempos de utilización de los forrajes.

A pesar de que la avena es el principal cultivo forrajero de invierno en esta región y coloca a Coahuila como el quinto productor a nivel nacional (SIAP, 2015), el trigo es considerado buena opción para producción de forraje. Para obtener nuevos genotipos con alto rendimiento, los fitomejoradores buscan nuevas metodologías para evaluar múltiples genotipos en corto tiempo (Jackson, 2001). Analizando así, la interacción genotipo ambiente (IGA), la cual es descrita como la inconsistencia del comportamiento entre genotipos de un ambiente a otro y cuando ocurre en gran proporción disminuye el progreso genético de la selección (Yang y Baker, 1991; Magari y Kang, 1993), destacando así su gran importancia.

A través del tiempo se han utilizado diversos parámetros para medir esta interacción, siendo el modelo AMMI el más efectivo en el análisis de ensayos multiregionales ya que captura una gran proporción de la suma de cuadrados de la IGA, separando en forma precisa los efectos principales de los de la interacción (Gauch, 1992).

Investigaciones sobre la interacción genotipo ambiente con el modelo AMMI se han realizado para la producción de grano en trigo (Rodríguez et al., 2011; Marza et al., 2016) y en sorgo (Williams et al., 2010), así como en la evaluación de la estabilidad y producción forrajera en triticales mediante cortes (Lozano et al., 2009), pero actualmente no existen trabajos sobre la IGA en las fracciones de forraje de trigo, solo se ha reportado la producción y valor nutritivo en fracciones de forraje de trigos imberbes (Zamora et al., 2016).

También se han encontrado reportes de estabilidad de rendimiento de grano en genotipos de trigo (Hortelano et al., 2013), para rendimiento de grano y forraje (Rodríguez et al., 2014) mediante el modelo de Eberhart y Russel (1966). Esta investigación tuvo como objetivo analizar la interacción genotipo ambiente en fracciones de forraje de 22 líneas de trigos harineros imberbes y tres testigos comerciales de otra especie a través de tres muestreos. 


\section{Materiales y métodos}

Se evaluaron 22 líneas de trigo harinero sin aristas más tres testigos comerciales: Avena cv. Cuauhtémoc, Cebada $c v$ GABYAN 95 y Triticale $c v$ Eronga 83 (Cuadro 1), durante los ciclos agrícolas otoño-invierno (O-I), en las localidades de Zaragoza, Coahuila, en el ciclo (O-I) 20172018 (Ambiente 1) y el ciclo O-I 2018-2019 (Ambiente 2), Navidad, Nuevo León (O-I) 2018-2019 (Ambiente 3) y San Ignacio, Municipio de San Pedro de las Colonias, Coahuila (O-I) 2018-2019 (Ambiente 4).

Cuadro 1. Material genético evaluado.

\begin{tabular}{cccccccc}
\hline Núm. & Variedad & Núm. & Variedad & Núm. & Variedad & Núm. & Variedad \\
\hline 1 & AN-249-99 & 8 & AN-216-09 & 14 & AN-228-09 & 20 & AN-409-13 \\
2 & AN-268-99 & 9 & AN-217-09 & 15 & AN-229-09 & 21 & AN-246-13 \\
3 & AN-263-99 & 10 & AN-218-09 & 16 & AN-264-09 & 22 & AN-310-03 \\
4 & AN-267-99 & 11 & AN-220-09 & 17 & AN-326-09 & 23 & Avena Cuauhtémoc \\
5 & AN-244-99 & 12 & AN-221-09 & 18 & AN-7-09 & 24 & Cebada Gabyan 95 \\
6 & AN-236-99 & 13 & AN-222-09 & 19 & AN-241-13 & 25 & Triticale Eronga 83 \\
7 & AN-209-09 & & & & & & \\
\hline
\end{tabular}

La combinación localidad y ciclo de producción se denominará genéricamente como ambiente. La información de las localidades de evaluación se cita en el Cuadro 2. En cada una de ellas se empleó un diseño de bloques completos al azar con tres repeticiones. La preparación del terreno consistió en labores tradicionales utilizadas para el establecimiento de cereales de grano pequeño de invierno en las regiones donde se siembra bajo condiciones de riego, consistentes en barbecho, rastreo, nivelación o cuadro y trazo de riego.

\section{Cuadro 2. Descripción de las localidades de evaluación.}

\begin{tabular}{cccccc}
\hline Localidad & Latitud & Longitud & Altitud $(\mathrm{m})$ & $\begin{array}{c}\text { Temperatura } \\
\text { media anual }\left({ }^{\circ} \mathrm{C}\right)\end{array}$ & $\begin{array}{c}\text { Precipitación media } \\
\text { anual }(\mathrm{mm})\end{array}$ \\
\hline Zaragoza & $28^{\circ} 28^{\prime} 31^{\prime \prime} \mathrm{N}$ & $100^{\circ} 55^{\prime} 10^{\prime} \mathrm{W}$ & 360 & 22 & 300 a 400 \\
San Ignacio & $25^{\circ} 45^{\prime} 32^{\prime} \mathrm{N}$ & $102^{\circ} 58^{\prime} 58^{\prime} \mathrm{W}$ & 1100 & 18 & 400 \\
Navidad & $25^{\circ} 04^{\prime} \mathrm{N}$ & $100^{\circ} 56^{\prime} \mathrm{W}$ & 1895 & 14 & 400 \\
\hline
\end{tabular}

La siembra se realizó manualmente, a chorrillo, con una densidad de siembra de $120 \mathrm{~kg} \mathrm{ha}^{-1}$, utilizando una dosis de fertilización de 120-80-00, aplicándose el nitrógeno de manera fraccionada: mitad a la siembra y otra mitad en el primer riego de auxilio y el fosforo todo a la siembra. En el ambiente 1 se sembró el 18 de diciembre de 2017, en el ambiente 2 el 6 de diciembre de 2018, el ambiente tres se sembró el 6 de febrero de 2019, en tanto que el ambiente 4 se estableció el 24 de noviembre de 2018.

Las malezas se controlaron de forma manual. Se realizaron tres muestreos de forraje (a los 75, 90 y 105 días después de la siembra) en todos los ambientes evaluados, con el fin de estimar la producción de materia seca de cada uno. El tamaño de la parcela experimental fue de $6.3 \mathrm{~m}^{2}(6$ 
hileras de $3 \mathrm{~m}$ de longitud por $0.35 \mathrm{~m}$ entre hileras) y la parcela útil fue de $0.175 \mathrm{~m}$. En cada muestreo se cortó $50 \mathrm{~cm}$ de una de las hileras con competencia completa, a una altura de $5 \mathrm{~cm}$ sobre la superficie del suelo.

El material cosechado en cada muestreo se separó manualmente en hojas, tallos y espigas, luego secado en asoleadero hasta obtener peso constante para determinar peso seco de hojas (PSH), tallos (PST), y espigas (PSE), con la suma de estos tres componentes se obtuvo el forraje seco total (FSTOT), siendo registrados en $\mathrm{tha}^{-1}$. La información de los ensayos se analizó como bloques completos al azar en forma combinada a través de ambientes para detectar la interacción genotipo ambiente y el análisis de la interacción genotipo ambiente se realizó bajo el siguiente modelo AMMI: $\mathrm{N}, \mathrm{Y}_{\mathrm{ij}}=\mu+\mathrm{g}_{\mathrm{i}}+\mathrm{e}_{\mathrm{j}}+\sum=\lambda_{\mathrm{k}} \alpha_{\mathrm{ik}} \gamma_{\mathrm{jk}}+\mathrm{R}_{\mathrm{ij}}, \mathrm{k}=1$. Donde: $\mathrm{Y}_{\mathrm{ij}}=$ rendimiento del $\mathrm{i}$-ésimo genotipo en el j-ésimo ambiente, $\mu=$ media general, $\mathrm{g}_{\mathrm{i}}=$ efecto del $\mathrm{i}$-ésimo genotipo, $\mathrm{e}_{\mathrm{j}}=$ efecto del $\mathrm{j}$-ésimo ambiente, $\lambda_{\mathrm{k}}=$ raíz cuadrada del valor propio del k-ésimo eje del ACP, $\alpha_{\mathrm{ik}} \gamma_{\mathrm{jk}}=$ calificación del ACP para el k-ésimo eje del i-ésimo genotipo y j-ésimo ambiente y $\mathrm{R}_{\mathrm{ij}}=$ residual del modelo.

Las calificaciones del análisis de componentes principales (ACP) para los ambientes y genotipos están expresadas como unidades del valor propio correspondiente por la raíz cuadrada del valor propio (Zobel et al., 1988). La suma de cuadrados de la interacción genotipo-ambiente se subdivide en ejes del ACP, donde el eje $\mathrm{k}$ posee $\mathrm{g}+\mathrm{e}-1$-2k grados de libertad, donde $\mathrm{g}$ y e representan el número de genotipos y ambientes, respectivamente. Normalmente son retenidos en el modelo sólo los dos primeros componentes principales (CP), los restantes son enviados al residual.

Las calificaciones asignadas a los genotipos pueden tomar valores positivos o negativos con respecto al $\mathrm{CP}$, siendo considerados genotipos estables aquellos que poseen valores cercanos a cero (menor interacción), valores mayores indican una mayor interacción con los ambientes y dependiendo del signo y el cuadrante de la gráfica generada se realiza una descripción más amplia de los genotipos y ambientes. Adicionalmente los genotipos fueron calificados como deseables si poseen un rendimiento superior a la media general del experimento aunado a menores interacciones con los ambientes. Los análisis se realizaron mediante el programa SAS (1989).

\section{Resultados y discusión}

En el primer muestreo todas las fracciones de forraje y el forraje seco total (FSTOT) presentaron significancia estadística $(p \leq 0.01)$ en la interacción genotipo ambiente (IGA) (Cuadro 3), de acuerdo con el modelo de efectos principales aditivos y de interacción multiplicativa (AMMI), realizado con la rutina desarrollada por Vargas y Crossa (2000) que contempla las repeticiones como un factor principal.

El análisis mostró que la IGA es explicada con los primeros dos componentes principales (CP), donde la explicación más baja fue del orden de $82 \%$ y correspondió al $\mathrm{FSH}$, siendo este porcentaje el más bajo obtenido; mientras que para FSTOT y FST, se explicó más de $85 \%$ a diferencia del FSE que fue explicada en $100 \%$, únicamente con el primer CP, siendo estos porcentajes mayores a los reportados por Lozano et al. (2009), lo cual permite una explicación confiable de la IGA, en tanto sea mayor de 75\% (Crossa, 1990). En el Cuadro 3 se aprecia que el primer componente resultó altamente significativo para todas las variables, en tanto que el segundo componente mostró significancia al $(p \leq 0.05)$ únicamente en la variable FSH. 
Cuadro 3. Cuadrados medios y significancia del AMMI para el primer muestreo.

\begin{tabular}{cccccccccc}
\hline FV & GL & FSTOT & & FST & & FSE & \multicolumn{2}{c}{ FSH } & \\
\hline Repeticiones (Rep) & 2 & 5.571 & $* *$ & 1.228 & $* *$ & 0.001 & & 1.585 & $* *$ \\
Ambientes (Amb) & 3 & 30.285 & $* *$ & 11.569 & $* *$ & 0.045 & $* *$ & 9.846 & $* *$ \\
Genotipos (Gen) & 24 & 1.84 & $* *$ & 0.976 & $* *$ & 0.008 & $* *$ & 0.347 & $* *$ \\
Amb x Gen & 72 & 0.699 & $* *$ & 0.223 & $* *$ & 0.008 & $* *$ & 0.169 & $* *$ \\
CP1 & 26 & 1.219 & $* *$ & 0.413 & $* *$ & 0.024 & $* *$ & 0.221 & $* *$ \\
CP2 & 24 & 0.495 & & 0.134 & & 0 & & 0.181 & $*$ \\
Residual & 22 & 0.306 & & 0.096 & & 0 & & 0.095 & \\
\hline
\end{tabular}

$\mathrm{FV}=$ fuente de variación; $\mathrm{GL}=$ grados de libertad. $\mathrm{FSTOT}=$ forraje seco total; $\mathrm{FST}=$ forraje seco de tallos; $\mathrm{FSE}=$ forraje seco de espigas; $\mathrm{FSH}=$ forraje seco de hojas.

Con los datos de rendimiento y el componente principal 1 del análisis AMMI, se elaboró la Figura 1, la cual permitió calificar como deseables en producción de FSTOT en el primer muestreo a los genotipos 15 (AN-229-09), 2 (AN-268-99), 19 (AN-241-13) y 7 (AN-209-09), al obtener rendimientos superiores a la media general $\left(3.25 \mathrm{t} \mathrm{ha}^{-1}\right)$ y mostrar interacciones pequeñas y negativas. El genotipo 3 (AN-263-99) también superó la media general, pero exhibió interacciones positivas.

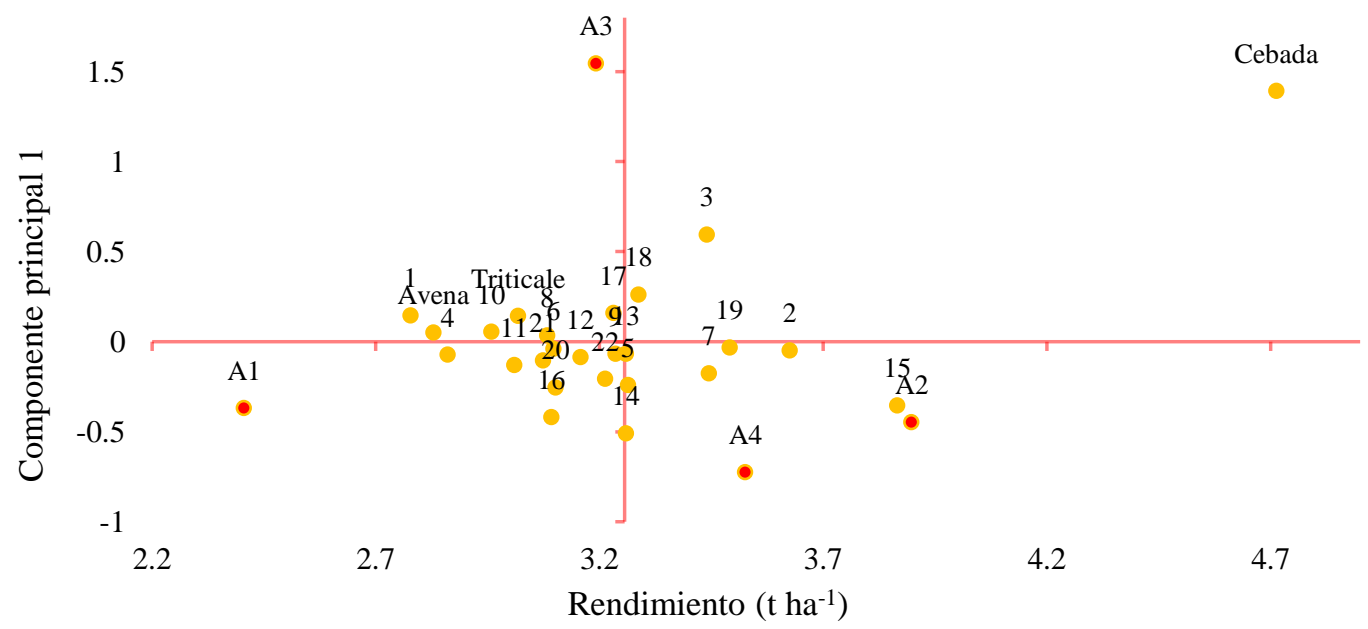

Figura 1. Genotipos y ambientes (A) con base en el rendimiento de FSTOT y primer CP del AMMI (IGA), en el primer muestreo

Cabe señalar, que a los 75 días después de la siembra (dds), el genotipo más rendidor fue GABYAN 95 con $4.71 \mathrm{t} \mathrm{ha}^{-1}$, con interacciones grandes y positivas; éste hecho es explicado principalmente por la precocidad que presenta la cebada, siendo una característica favorable que se refleja en menor tiempo de ocupación del terreno (Colín et al., 2007). La avena cv Cuauhtémoc fue la menos rendidora mostrando interacciones cercanas a cero, siendo superada por los trigos y los testigos comerciales de triticale y cebada, confirmando así la existencia de trigos forrajeros con mayor producción que la avena $c v$ Cuauhtémoc a los 75 dds. El ambiente 3 (Navidad O-I 2018-2019) provocó interacciones grandes y positivas, debido posiblemente a que la temperatura haya acelerado la fenología de los genotipos (Karsai et al., 2008), dada la fecha tardía de siembra en este 
ambiente que promedió en los meses del experimento una temperatura máxima de $27.8^{\circ} \mathrm{C}$ y una mínima de $15.2{ }^{\circ} \mathrm{C}$ acorde a los registros del Servicio Meteorológico Nacional (SMN, 2019), mientras que los ambientes 1 (Zaragoza O-I 2017-2018), 2 (Zaragoza O-I 2018-2019) y 4 (San Ignacio O-I 2018-2019) provocaron interacciones negativas y estos tres ambientes presentaron temperaturas promedio más bajas que el ambiente 3 durante el período de evaluación.

El genotipo 15 (AN-229-09) se asoció fuertemente al ambiente 2 (Zaragoza O-I 2018-2019), siendo éste el más productivo. En Navidad O-I 2018-2019 (A3), el genotipo 3 (AN-263-99) y cebada cv. Gabyan 95 se asociaron de forma positiva y en Zaragoza O-I 2017-2018 (A1) siendo el ambiente que mostró menor rendimiento, se asociaron los genotipos 4 (AN-267-99), 11 (AN-220-09), 16 (AN-264-09) y 20 (AN-409-13). Al ambiente 1 mostró las temperaturas máximas promedio más bajas de los ambientes estudiados, por lo que de acuerdo con), retrasó la etapa fenológica de los cereales evaluados y por ende su biomasa. Las asociaciones de los genotipos con los ambientes mencionados indican que producirán una buena cantidad de forraje seco total en el ambiente con el que se asociaron.

Al graficar la IGA explicada por el primer CP del AMMI y la producción de tallos (Figura 2), se encontró que GABYAN 95 obtuvo la mayor producción de tallos, mostrando interacciones grandes y positivas, seguida por los genotipos 15 (AN-229-09), 2 (AN-268-99), 19 (AN-241-13) y 21 (AN246-13) los cuales mostraron rendimientos superiores a la media general $\left(1.41 \mathrm{t} \mathrm{ha}^{-1}\right) \mathrm{e}$ interacciones pequeñas y positivas excepto los genotipos 15 (AN-229-09) y 21 (AN-246-13) con interacciones negativas.

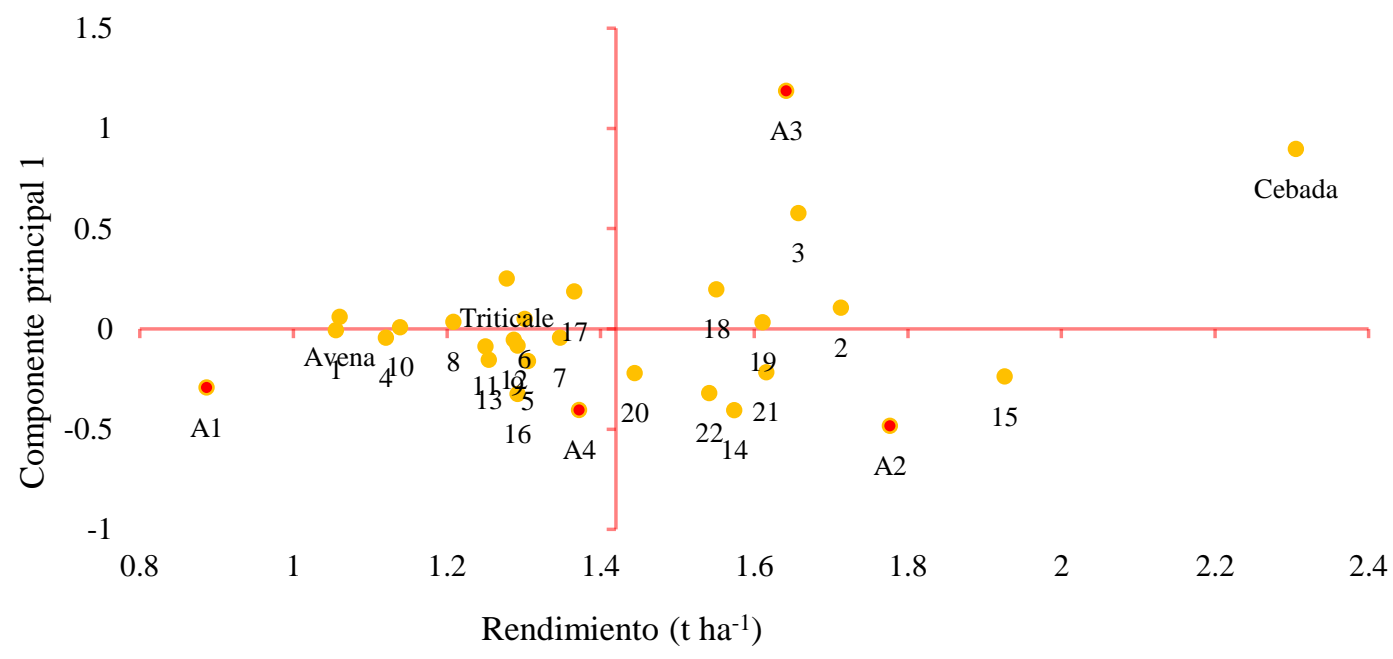

Figura 2. Genotipos y ambiente (A) con base en el rendimiento de FST y primer CP del AMMI (IGA) en el primer muestreo.

El genotipo 3 (AN-263-99) también superó la media general, pero exhibió interacciones grandes y positivas. La avena $c v$ Cuauhtémoc presentó en esta variable el rendimiento más bajo y cero interacciones. El ambiente 3 (Navidad, O-I 2018-2019) provocó interacciones positivas y los ambientes 1, 2 y 4 (Zaragoza O-I 2017-2018, O-I 2018-2019 y San Ignacio O-I 2018-2019) interacciones negativas, tal como sucedió en la variable FSTOT. 
Al ambiente 2 (Zaragoza, O-I 2018-2019) se asociaron los genotipos 15 (AN-229-09), 21 (AN246-13), 22 (AN-310-03) y 14 (AN-228-09), siendo éste el ambiente más productivo en tallos, y al ambiente 3 (Navidad, O-I 2018-2019) se asociaron genotipos como el 3 (AN-263-99) y Gabyan 95, mientras que al ambiente 1 (Zaragoza O-I 2017-2018), el menos favorable, al cual se asociaron los genotipos 1 (AN-249-99), 4 (AN-267-99) y 10 (AN-218-09).

Se calificaron como deseables para producción de forraje seco de hojas a los genotipos 13 (AN222-09), 5 (AN-244-99), 9 (AN-217-09) y 7 (AN-209-09), al tener una producción mayor a la media general $\left(1.82 \mathrm{t} \mathrm{ha}^{-1}\right)$ y mostrar interacciones positivas cercanas a cero, a excepción del genotipo 7 (AN-209-09) al presentar interacciones grandes (Figura 3). Cebada $c v$ Gabyan 95 obtuvo la mayor producción de hojas, presentando interacciones grandes y negativas, sin embargo, uno de los genotipos evaluados de trigo (21) con interacciones pequeñas y negativas se colocó como el de menor producción de hojas.

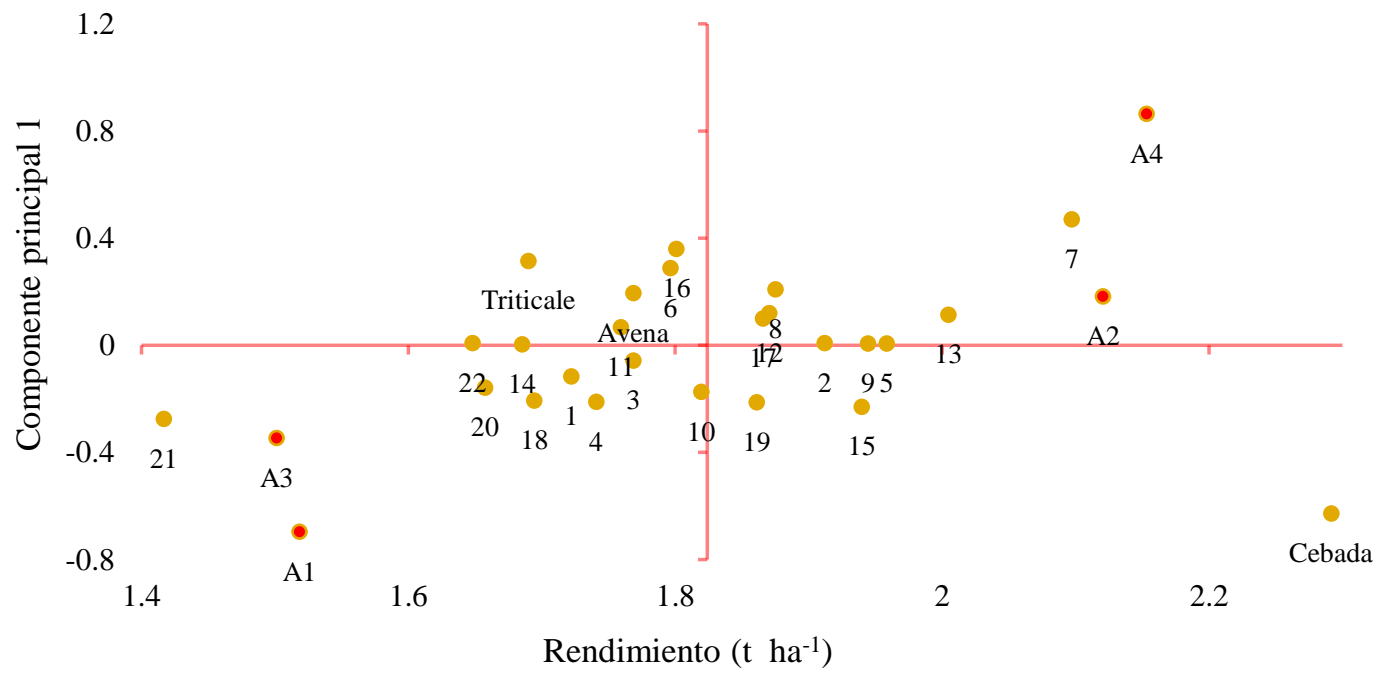

Figura 3. Genotipos y ambiente (A) con base en el rendimiento de FSH y primer CP del AMMI (IGA) en el primer muestreo.

La avena $c v$ Cuauhtémoc presentó un rendimiento favorable, pero sin superar la media general y con interacciones cercanas a cero. Con interacciones positivas se mantuvieron los ambientes 2 (Zaragoza O-I 2018-2019) y 4 (San Ignacio O-I 2018-2019), éste último ambiente fue considerado el más adecuado para producción de hojas, al cual se asoció positivamente el genotipo 7 (AN-20909), de forma contraria, los ambientes 1 (Zaragoza O-I 2017-2018) y 3 (Navidad O-I 2018-2019) provocaron interacciones negativas, existiendo entre estos muy poca diferencia en producción de hojas, aun así, se distinguió al ambiente 3 como el menos favorable, donde el genotipo 21 (AN246-13) mantuvo asociación. La producción de hojas es de cierta importancia, ya que los genotipos al presentar mayor cantidad de hojas se consideran para producción de heno (Feyissa et al., 2008).

Al analizar la IGA explicada por el primer CP del análisis AMMI y la producción de espigas se calificó a los genotipos 21 (AN-246-13), 18 (AN-7-09), 22 (AN-310-03), 19 (AN-241-13) y 3 (AN263-99) como deseables al superar la media general $\left(0.0122 \mathrm{t} \mathrm{ha}^{-1}\right)$ y mostrar interacciones positivas cercanas a cero (Figura 4). La cebada $c v$ Gabyan 95 fue el genotipo con la mayor producción de espigas con un rendimiento de $0.115 \mathrm{t} \mathrm{ha}^{-1} \mathrm{e}$ interacciones grandes y positivas. 


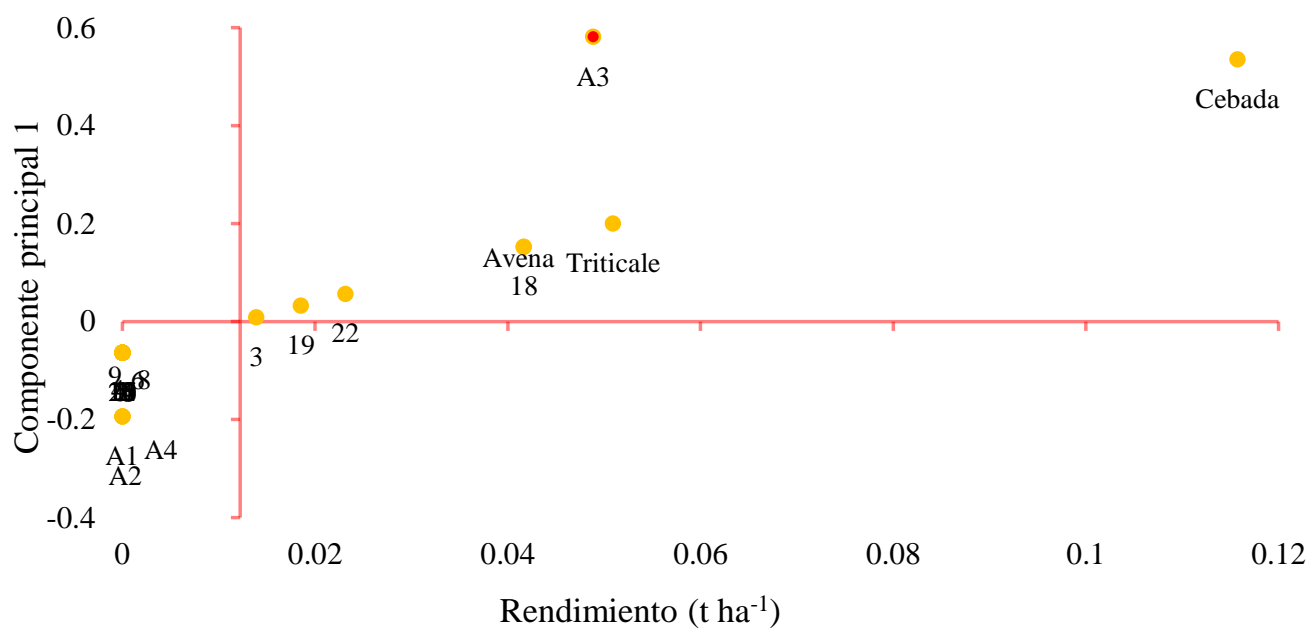

Figura 4. Genotipos y ambientes (A) con base en el rendimiento de FSE y primer CP del AMMI (IGA) en el primer muestreo.

Los testigos triticale $c v$ Eronga 83 y avena $c v$ Cuauhtémoc también se denominaron deseables al superar la media general, exhibiendo interacciones positivas; de acuerdo con la precocidad que presentaban estos testigos, mostraron una etapa fenológica de emergencia de espiga, pero con rendimiento de forraje bajo, coincidiendo con Torres et al. (2019) quienes reportaron a los 90 dds haber encontrado en avena y triticale una etapa de emergencia de espiga con bajos rendimientos de forraje.

Únicamente se logra distinguir al ambiente 2 (Zaragoza O-I 2018-2019) que provocó interacciones negativas y el ambiente 3 (Navidad O-I 2018-2019) interacciones positivas, siendo este ambiente el de mayor producción, donde los testigos evaluados mantuvieron asociación positiva. Cabe mencionar que la mayoría de los genotipos aún no presentaban espigas en este primer muestreo (Figura 4).

Para el segundo muestreo el análisis de varianza exhibió diferencias $(p \leq 0.01)$ para FSE en la interacción genotipo ambiente, sugiriendo que en las fracciones de tallos y hojas y en el forraje seco total los genotipos tuvieron un comportamiento similar sobre los ambientes de prueba, lo cual es deseable en los sistemas de producción y permite su recomendación en los ambientes de prueba y áreas de características similares. El análisis AMMI explicó 84\% de la IGA en el FSE, con los primeros dos componentes.

Detectando que los dos primeros componentes principales exhibieron alta significancia estadística $(p \leq 0.01)$ en el FSE, y significancia $(p \leq 0.05)$ para el primer componente en el FSH, a pesar de que el análisis de varianza no detectó significancia en la interacción genotipo ambiente del forraje seco de hojas, sugiriendo que el análisis AMMI de la IGA puede considerar significativas variaciones pequeñas en la IGA, de manera similar a cuando las pruebas de medias poco exigentes declaran significancia cuando el análisis de varianza declaró no significancia en la variable en estudio. El segundo CP resultó significativo ( $p \leq 0.01)$ solamente en FSE (Cuadro 4). 
Cuadro 4. Cuadrados medios y significancia del AMMI para el segundo muestreo.

\begin{tabular}{cccccc}
\hline FV & GL & FSTOT & FST & FSE & FSH \\
\hline Repeticiones (Rep) & 2 & 1.868 & 0.547 & 0.108 & 0.125 \\
Ambientes (Amb) & 3 & $157.557^{* *}$ & $56.087^{* *}$ & $16.979^{* *}$ & $85.967^{* *}$ \\
Genotipos (Gen) & 24 & $5.339^{* *}$ & $2.478^{* *}$ & $0.576^{* *}$ & $1.29^{* *}$ \\
Amb x Gen & 72 & 1.155 & 0.471 & $0.165^{* *}$ & 0.266 \\
CP1 & 26 & 1.839 & 0.609 & $0.282^{* *}$ & $0.428^{*}$ \\
CP2 & 24 & 0.855 & 0.531 & $0.109^{* *}$ & 0.246 \\
Residual & 22 & 0.674 & 0.242 & 0.086 & 0.095 \\
\hline
\end{tabular}

$\mathrm{FV}=$ fuente de variación; $\mathrm{GL}=$ grados de libertad. $\mathrm{FSTOT}=$ forraje seco total; $\mathrm{FST}=$ forraje seco de tallos; $\mathrm{FSE}=$ forraje seco de espigas; $\mathrm{FSH}=$ forraje seco de hojas.

Con los resultados del forraje seco de espigas y el primer componente principal del análisis AMMI se generó la Figura 5, donde el genotipo 21 (AN-246-13) se colocó como el más productivo y mostrándose cerca de la línea que marca cero interacciones. Así también los genotipos de trigo: 22 (AN-310-03), 2 (AN-268-99), 19 (AN-241-13), 20 (AN-409-13), 3 (AN-263-99), 18 (AN-7-09), 15 (AN-229-09), 14 (AN-228-09), 17 (AN-326-09) y triticale, superaron la media general y exhibieron interacciones negativas cercanas a cero, calificándolos como deseables en la producción de espigas, comportamiento debido a la respuesta positiva que presentaron al incremento en la temperatura en el ambiente 3, confirmando lo reportado por Karsai et al. (2008).

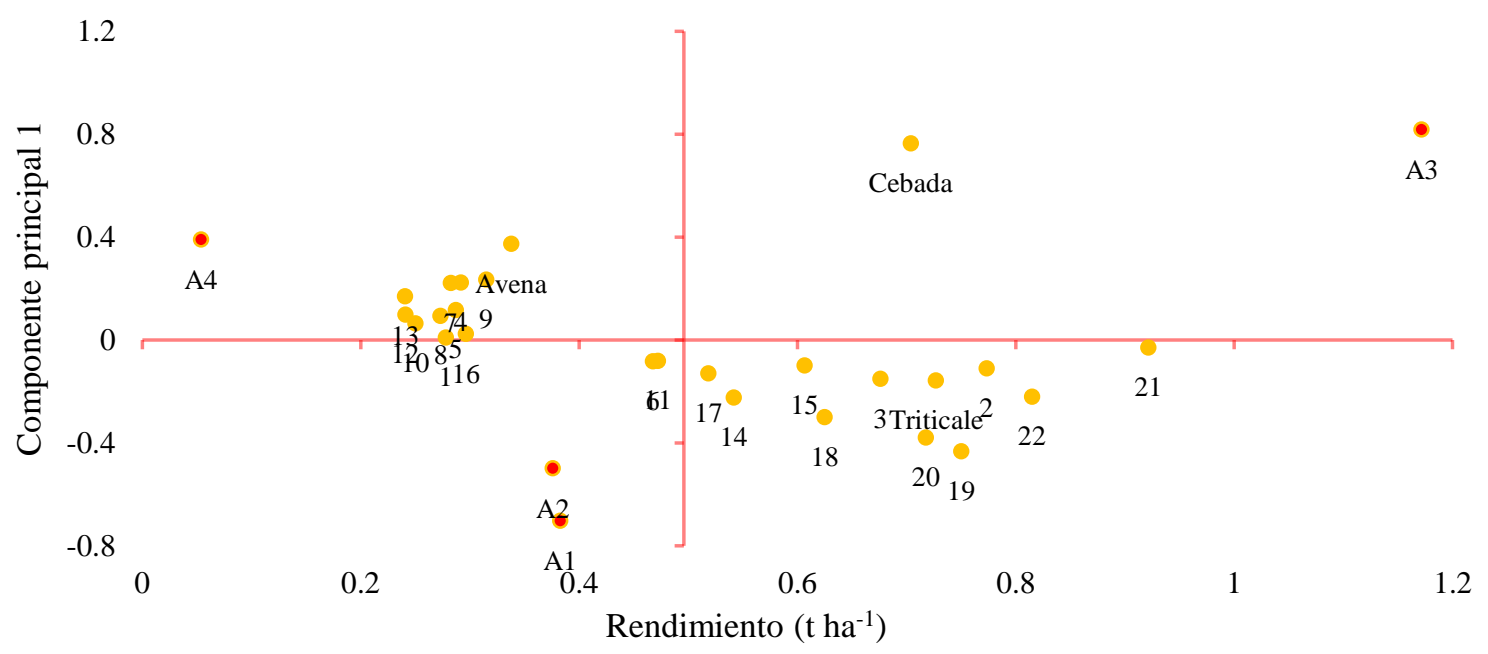

Figura 5. Genotipos y ambientes (A) con base en el rendimiento de FSE y el primer CP del AMMI (IGA) en el segundo muestreo.

Los testigos cebada y triticale mostraron una producción similar, pero con interacciones opuestas, diferencia en comportamiento debida principalmente a la precocidad de la cebada que le permitió espigar más rápidamente. Los ambientes 3 (Navidad O-I 2018-2019) y 4 (San Ignacio O-I 20182019) provocaron interacciones positivas y los ambientes 1 (Zaragoza O-I 2017-2018) y 2 (Zaragoza O-I 2018-2019) interacciones negativas, de esta manera. 
Se observó la asociación que mantuvieron los genotipos 13 (AN-222-09), 12 (AN-221-09), 10 (AN-218-09) y la avena al ambiente 4 (San Ignacio O-I 2018-2019), siendo este ambiente el menos adecuado para producción de espigas y el ambiente 3 (Navidad O-I 2018-2019) se consideró el más favorable, dado que alcanzó temperaturas máximas más elevadas que el resto de ambiente y donde la cebada $c v$ Gabyan 95 y el genotipo 21 (AN-246-13) mantuvieron asociación positiva (Figura 6), debido a su mayor precocidad que se vio favorecida por temperaturas más elevadas (Karsai et al., 2008).

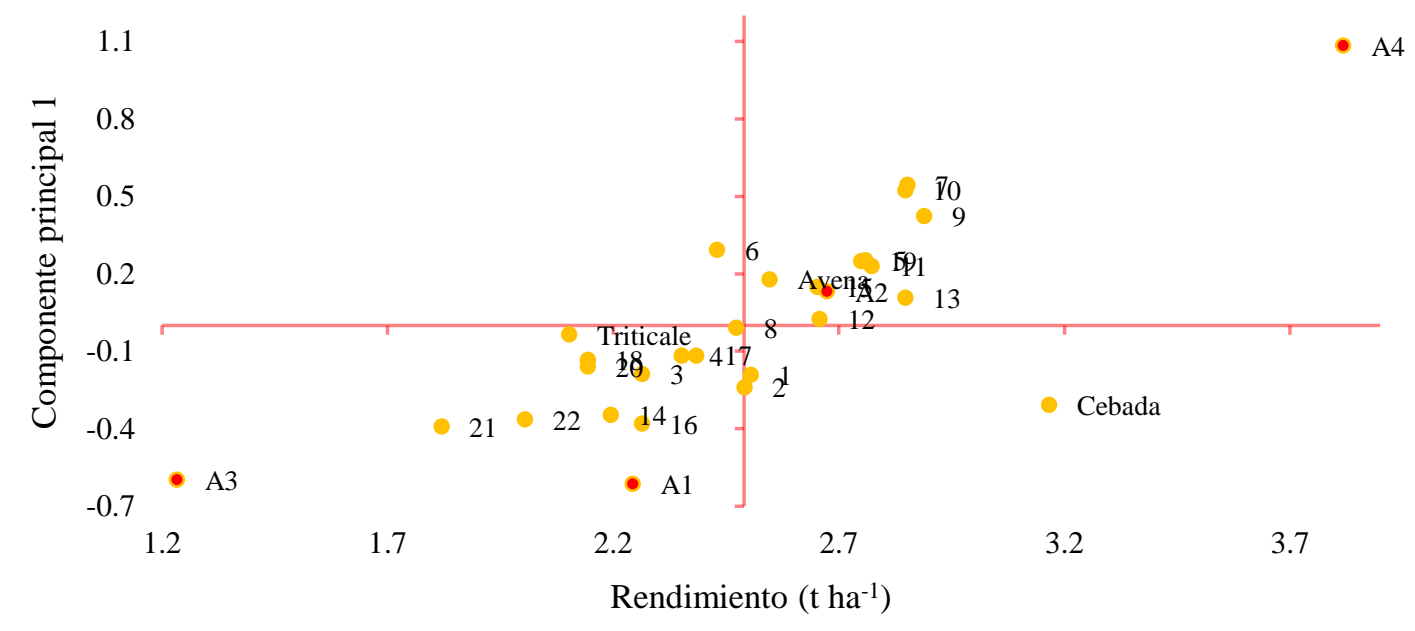

Figura 6. Genotipos y ambientes (A) con base en el rendimiento de FSH y primer CP del AMMI (IGA) en el segundo muestreo.

Cabe mencionar, que el análisis de varianza no exhibió diferencias significativas para la producción de hojas, pero el componente principal 1 del análisis AMMI si fue significativo $(p \leq 0.05)$, logrando identificar a los genotipos 13 (AN-222-09), 11 (AN-220-09) y 19 (AN-241-13) que presentaron interacciones positivas cercanas a cero, y a los genotipos 9 (AN-217-09), 10 (AN-218-09) y 7 (AN209-09) también con interacciones positivas, pero más grandes, calificándose como deseables al superar la media general $\left(2.49 \mathrm{tha}^{-1}\right)$.

Gabyan 95 fue el genotipo con la mayor producción de hojas con un rendimiento de $3.16 \mathrm{t} \mathrm{ha}^{-1}$, exhibiendo interacciones negativas; tal como sucedió a los 75 dds, el genotipo 21 (AN-246-13) se colocó en último lugar de acuerdo con la baja producción de hojas que presentó. Los ambientes 2 (Zaragoza O-I 2018-2019) y 4 (San Ignacio O-I 2018-2019) provocaron interacciones positivas y de forma contraria los ambientes 1 (Zaragoza O-I 2017-2018) y 3 (Navidad O-I 2018-2019) provocaron interacciones grandes y negativas. El ambiente más productivo fue el ambiente 4 (San Ignacio O-I 2018-2019) al cual ningún genotipo mantuvo asociación evidente, mientras que a Navidad O-I 2018-2019 (A3), ambiente menos favorable se asoció el genotipo 21 (AN-246-13).

Para el tercer muestreo realizado a los 105 dds, el análisis de varianza exhibió diferencias altamente significativas en la interacción genotipo ambiente para la variable FSE y significancia al $(p \leq 0.05)$ para FSH, mientras que para el FSTOT y FST no hubo significancia alguna. Tal como sucedió en el segundo muestreo, FSE continúo manifestando IGA y en este muestreo FSH lo hizo de manera significativa, aunque no haya existido diferencia estadística en algunas de las variables productivas, se realizó el análisis AMMI, en el cual dicho análisis explicó $82 \%$ para forraje seco de hojas y $87 \%$ para forraje seco de espigas, utilizando los primeros dos $\mathrm{CP}$. 
El primer componente principal mostró significancia estadística al $(p \leq 0.01)$ para FSE y FSH y significancia al $(p \leq 0.05)$ para FST, mientras que el segundo componente no mostró significancia estadística para ninguna variable (Cuadro 5).

Cuadro 5. Cuadrados medios y significancia del AMMI para el tercer muestreo.

\begin{tabular}{cccccc}
\hline FV & GL & FSTOT & FST & FSE & FSH \\
\hline Repeticiones (Rep) & 2 & 0.825 & 0.366 & 0.221 & 0.571 \\
Ambientes (Amb) & 3 & $445.737^{* *}$ & $224.244^{* *}$ & $26.429^{* *}$ & $120.419^{* *}$ \\
Genotipos (Gen) & 24 & $8.889^{* *}$ & $3.185^{* *}$ & $2.973^{* *}$ & $1.968^{* *}$ \\
Amb x Gen & 72 & 2.16 & 0.989 & $0.403^{* *}$ & $0.55^{*}$ \\
CP1 & 26 & 3.365 & $1.438^{*}$ & $0.681^{* *}$ & $0.877^{* *}$ \\
CP2 & 24 & 1.451 & 0.737 & 0.321 & 0.417 \\
Residual & 22 & 1.509 & 0.735 & 0.165 & 0.309 \\
\hline
\end{tabular}

$\mathrm{FV}=$ fuente de variación; GL= grados de libertad. FSTOT = forraje seco total; FST= forraje seco de tallos; FSE= forraje seco de espigas; $\mathrm{FSH}=$ forraje seco de hojas.

Con base a los resultados obtenidos de la producción de tallos y el primer componente principal del análisis AMMI se elaboró la Figura 7, donde los genotipos de trigo: 15 (AN-229-09), 20 (AN409-13) y 14 (AN-228-09), al colocarse como los trigos más productivos y acercándose a la línea que marca cero interacciones, seguido de los genotipos 9 (AN-217-09), 22 (AN-310-03) y 18 (AN7-09) con interacciones positivas y lo trigos 19 (AN-241-13), 21 (AN-246-13) y 2 (AN-268-99) con interacciones negativas, denominados como deseables al superar la media general $\left(4.7 \mathrm{t} \mathrm{ha}^{-1}\right)$.

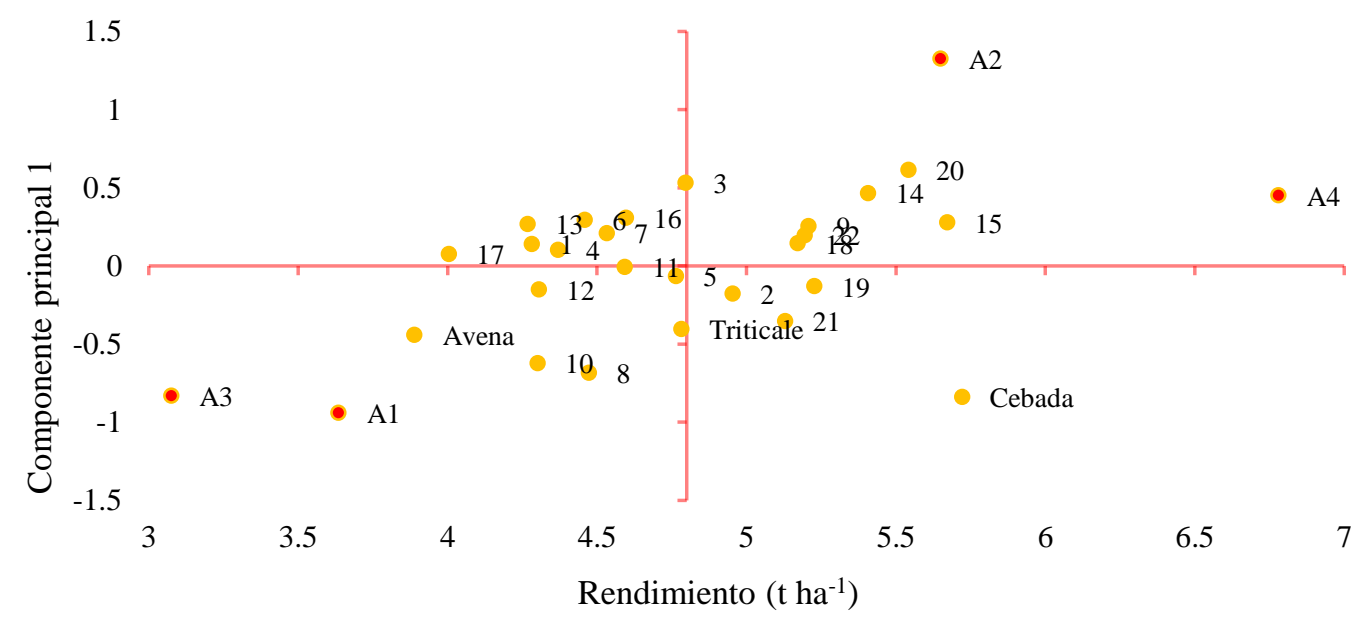

Figura 7. Genotipos y ambientes (A) con base en el rendimiento de FST y primer CP del AMMI (IGA) en el tercer muestreo.

La cebada Gabyan95 mostró un rendimiento ligeramente superior al de los trigos ya mencionados con la única diferencia de presentar interacciones grandes y negativas. De acuerdo con estos resultados obtenidos, se coincide con Feyissa et al. (2008) al reportar que los tallos representan más de $50 \%$ de la producción de forraje seco total en todos los genotipos evaluados. La avena fue el genotipo de menor producción de tallos, exhibiendo interacciones pequeñas y negativas, asociándose al ambiente 1 (Zaragoza O-I 2017-2018) junto con los genotipos 10 (AN-218-09) y 8 (AN-216-09) y al ambiente 2 (Zaragoza O-I 2018-2019) se asociaron los trigos: 15 (AN-229-09), 20 (AN-409-13) y 14 (AN-228-09). 
Estos testigos mencionados fueron aumentando casi en $100 \%$ su producción de tallos a través de los muestreos realizados, presentando los siguientes rendimientos para cebada: $2.3,4$. 43 y $5.7 \mathrm{t}$ $\mathrm{ha}^{-1}$ y para la avena: 1.1, 2.2 y $3.8 \mathrm{t} \mathrm{ha}^{-1}$, para el primero, segundo y tercer muestreo, respectivamente. Por otro lado, los ambientes 2 (Zaragoza O-I 2018-2019) y 4 (San Ignacio 20182019) provocaron interacciones positivas y los ambientes 1 (Zaragoza 2017-2018) y 3 (Navidad O-I 2018-2019) provocaron interacciones negativas, reportando a Navidad O-I 2018-2019 como el ambiente menos productivo.

\section{Conclusiones}

Con base en los resultados obtenidos se concluye que, en las etapas tempranas de desarrollo (75 dds) ser manifestó IGA en el forraje seco y sus fracciones, mientras que en etapas más avanzadas (90 y 105 dds), solo el peso seco de hojas y espigas mostraron interacción. La ausencia de IGA en FSTOT y FST en el segundo y tercer muestreo, es una característica deseable, ya que esto sugiere que los genotipos poseen una estabilidad de producción, a pesar de que la fracción de espigas continuó mostrando interacción en dichos muestreos.

La etapa donde menos IGA se presentó fue a los 90 dds, logrando detectar que el ambiente 3 (Navidad O-I 2018-2019) promovió mayor producción de espigas y el ambiente 4 (San Ignacio OI 2018-2019) favoreció la producción de hojas. Trece genotipos de trigo fueron considerados deseables para producción de forraje, junto con el testigo GABYAN 95 que fue el genotipo más productivo en todos los muestreos realizados. De acuerdo con este estudio los trigos forrajeros evaluados son una alternativa para producción de materia seca en invierno y a partir de los 90 dds presentaron baja o nula IGA.

\section{Literatura citada}

Braun, H. J. and Sãulescu, N. N. 2002. Breeding winter and facultative wheat. In: Curtis, B. C.; Rajaram, S. and Macpherson, H. (Ed.). Bread wheat: improvement and production. FAO Plant Production and Protection Series. Italy. FAO 2002. 554 p.

Cash, S. D.; Staber, L. M. M.; Wichman, D. M. and Hensleigh, P. F. 2004. Forage yield, quality and nitrate concentration of barley grown under irrigation. USA. Montana State University. $4 \mathrm{p}$.

Cherney, J. H. and Marten, G. C. 1982. Small grain crop forage potential: I. biological and chemical determinants of quality and yield. USA. Crop. Sci. 22(2):227-231.

Colín, R. M.; Zamora, V. V. M.; Lozano, R. A. J.; Martínez, Z. G. y Torres, T. M. A. 2007. Caracterización y selección de nuevos genotipos imberbes de cebada forrajera para el norte y centro de México. Téc. Pec. Méx. 45(3):249-262.

Crossa, J. 1990. Statistical analysis of multilocation trials. USA. Adv. Agron. 44(1):55-85.

Eberhart, S. A. and Russell, W. A. 1966. Stability parameters for comparing varieties. USA. Crop Sci. 6(1):36-40.

FAO. 2005. Organización de las Naciones Unidas para la Alimentación y la Agricultura. www.fao.org/giews/.

Feyissa, F; Tolera, A. and Melaku, S. 2008. Proportions of morphological fractions of oats (Avena sativa L.) as affected by variety and growth stage. Livestock Res. Rural Development. 20(6). 
Gauch, H. G. 1992. Statistical analysis of regional yield trials: AMMI analysis of factorial designs. Elsevier, Amsterdam. The Netherlands. 278 p.

Hart, H. R.; Carlson, G. E. and Cloud, D. E. 1971. Cumulative effects of cutting management of forage yields and tiller densities of tall fescue and orchard grass. Agron. J. 63(4):895-898.

Hortelano, S. R. R.; Villaseñor, M. H. E.; Martínez, C. E.; Rodríguez, G. M. F.; Espitia, R. E. y Mariscal, A. L. A. 2013. Estabilidad de variedades de trigo recomendadas para siembras de temporal en los valles Altos de la Mesa Central. Rev. Mex. Cienc. Agríc. 4(5):713-725.

Hughes, H. D.; Health, M. E. y Metcalfe, D. S. 1974. Forrajes. (Ed.). CECSA, México, DF. 343-373 p.

Jackson, P. A. 2001. Directions for physiological research for breeding: issues from a breeding perspective. Reynolds, M. P.; Ortiz-Monasterio, J. I. and McNab, A. (Ed.). Application of Physiology in Wheat Breeding. Centro Internacional de Maíz y Trigo (CIMMYT). México, DF. 11-16 p.

Juskiw, P. E.; Helm, J. H. and Salmon, D. F. 2000. Forage yield and quality for monocrops and mixtures of small grain cereals. USA. Crop Sci. 40(1):138-147.

Karsai, I.; Szucs, P.; Kõszegi, B.; Hayes, P. M.; Casas, A.; Bedõ, Z. and Veisz, O. 2008. Effects of photo and thermo cycles on flowering time in barley: a genetical phenomics approach. $\mathrm{J}$. Exp. Bot. 59(10):2707-2715.

Lozano, R. A. J.; Zamora, V. V. M.; Ibarra, J. L.; Rodríguez, H. S. A.; De-Cruz, L. E. y De-Rosa, I. M. 2009. Análisis de la interacción genotipo ambiente mediante el modelo AMMI y potencial de producción de triticales forrajeros ( $X$ Triticosecale Wittm.). México. Universidad y Ciencia. Trópico Húmedo. 25(1):81-92.

Magari, R. and Kang, M. 1993. Genotype selection via a new yield stability statistic in maize yield trials. Euphytica 70(1):105-111.

Marza, F.; Butrón, R.; Quispe, F.; Gutiérrez, G. y Vaca, L. 2016. Rendimiento y estabilidad fenotípica de diez variedades internacionales de trigo harinero en zonas trigueras de Bolivia, 2015-2016. Revista de Investigación Agropecuaria y Forestal Boliviana. RIAFB. 4(9):22-34.

Rodríguez, G. R. E.; Paz, H. J. J.; Iñiguez, M. C. G.; Rueda, P. E. O.; Avendaño, R. L.; Cruz, V. M.; Ail, C. C. E.; Stoycheva, M.; Koytchev, Z. R.; Renganathan, P. y García, L. A. M. 2014. Estabilidad de rendimiento en trigo en Valle de Mexicali, México. Rev. Inter. Bot. Exp. 83(1):65-70.

Rodríguez, G.; Ponce, M. R. J. F.; Rueda P. E.O.; Avendaño, R. L.; Paz, H. J. J.; Santillano, C. J. y Cruz, V. M. 2011. Interacción genotipo-ambiente para la estabilidad de rendimiento de trigo en la región de Mexicali, B.C. México. Trop. Subtrop. Agroecosys. Mérida, Yucatán México. 14(2):543-558.

SAS. 1989. Institute Inc. SAS/STAT User's guide. Version 6. Fourth edition. SAS Institute Inc., Cary, NC. 943 p.

SIAP. 2015. Atlas agroalimentario 2015. Primera edición. Sistema de Información Agroalimentaria y Pesquera. Secretaria de Agricultura, Ganadería, Desarrollo Rural, Pesca y Alimentación (SAGARPA). México. 216 p.

SMN. 2019. Servicio Meteorológico Nacional. Centro Nacional de Prevención del Tiempo. https://smn.cna.gob.mx/es/climatologia/temperaturas-y-lluvias/resumenes-mensuales-de temperaturas-y-lluvias.

Torres, T. M. A.; Zamora, V. V. M.; Colín, R. M.; Foroughbakhch, P. R. y Ngangyo, H. M. 2019. Caracterización y agrupamiento de cebadas imberbes mediante sensores infrarrojos y rendimiento de forraje. Rev. Mex. Cienc. Agric. 10(5):1125-1137. 
Vargas, M. J. and Crossa, J. 2000. El análisis AMMI y la gráfica del biplot en SAS. Centro Internacional de Maíz y Trigo (CIMMYT). Unidad de Biometría y Estadística. México, DF. 42 p.

Williams, A. H.; Pecina, Q. V.; Zavala, G. F.; Montes, G. N.; Gámez, V. A. J.; Arcos, C. G.; García, G. M. A.; Montes, H. S. y Alcalá, S. L. 2010. Modelo de Finlay y Wilkinson vs. el modelo AMMI para analizar la interacción genotipo ambiente en sorgo. Rev. Mex. Cienc. Agríc. 33(2):117-123.

Yang, R. and Baker, R. 1991. Genotype environment interactions in two wheat crosses. USA. Crop Sci. 31(1):83-87.

Zamora, V. V. M.; Colín, R. M.; Torres, T. M. A.; Rodríguez, G. A. y Jaramillo, S. M. A. 2016. Producción y valor nutritivo en fracciones de forraje de trigos imberbes. Rev. Mex. Cienc. Agríc. 7(2):291-300.

Zobel, R. W.; Wright, M. J. and Gauch, H. G. 1988. Statistical analysis of a yield trial. USA. Agron. J. 80(3):388-393. 